\title{
Elevated Liver Enzymes and its Association with Type Two Diabetes Melli- tus: The Occurrence in Yemeni Population
}

\author{
Lotfi S Bin Dahman ${ }^{*}$, Mariam A Humam², Nabil S Musiaan ${ }^{3}$, Ahmed M Daakik $^{3}$, and Mohammed A Balfas ${ }^{4}$ \\ ${ }^{1}$ Medical Biochemistry Department, College of Medicine and Health Sciences, Hadhramout University, Mukalla 50511, Yemen \\ ${ }^{2}$ Pathology Department, College of Medicine and Health Sciences, Hadhramout University, Mukalla 50511, Yemen \\ ${ }^{3}$ Internal Medicine Department, College of Medicine and Health Sciences, Hadhramout University Mukalla 50511, Yemen \\ ${ }^{4}$ Medical Physiology Department, College of Medicine and Health Sciences, Hadhramout University, Mukalla 50511, Yemen
}

*Corresponding author: Lotfi S Bin Dahman, Medical Biochemistry Department, College of Medicine and Health Sciences, Hadhramout University, Mukalla 50511, Yemen, E-mail: lotfydahman@hu.edu.ye

Received: 27 Feb, 2021 | Accepted: 08 Apr, 2021 | Published: 15 Apr, 2021

Citation: Dahman LSB, Humam MA, Musiaan NS, Daakik AM, Balfas MA (2021) Elevated Liver Enzymes and its Association with Type Two Diabetes Mellitus: The Occurrence in Yemeni Population. Int J Endocrinol Metab Disord 7(1): dx.doi.org/10.16966/2380-548X.175

Copyright: (C) 2021 Dahman LSB, et al. This is an open-access article distributed under the terms of the Creative Commons Attribution License, which permits unrestricted use, distribution, and reproduction in any medium, provided the original author and source are credited.

\section{Abstract}

This case-control study was aimed to investigate the association between elevated liver enzymes and type 2 diabetes mellitus (T2DM) in Yemeni patients. This present study comprising $142 \mathrm{~T} 2 \mathrm{D}$ patients and 142 healthy control subjects were recruited from the diabetic outpatient clinic of Ibn-Sina Hospital in Mukalla during the period from $1^{\text {st }}$ January to $30^{\text {th }}$ May 2020. Serum fasting blood glucose (FBG), total cholesterol, triglyceride, high-density lipoprotein cholesterol (HDL-C), alanine aminotransferase (ALT), aspartate aminotransferase (AST), and gamma-glutamyl transferase (GGT) were analyzed using the Cobas Integra Plus 400 autoanalyzer. Anthropometric and blood pressure measurements were taken from each participant. T2D patients had significantly higher FBG $(P \leq 0.0001)$, total cholesterol $(P \leq 0.0001), L D L-C(P \leq 0.0001)$, and GGT $(P \leq 0.0001)$ while, HDL-C was significantly lower in T2D patients $(P=0.021)$. Serum ALT and GGT levels were significantly associated with increased incident T2D risk ( $P=0.006$ for $A L T$ and 0.022 for GGT), and the odds ratios at $95 \% \mathrm{Cl}$ comparing the highest versus lower tertiles of ALT and GGT were $2.75(2.01-3.48$ ) and 1.17(1.83-6.42) respectively. In conclusion, markedly elevated ALT and GGT are positively associated with increased blood glucose levels and are used as predictive biomarkers for developing a higher risk of diabetes. Thus, routine screening of ALT and GGT in T2D patients is recommended for the early detection of liver disorders.

Keywords: Alanine aminotransferase; Gamma-glutamyl transferase; Type 2 diabetes mellitus; Yemeni patients

\section{Introduction}

Diabetes mellitus is a metabolic disorder characterized by chronic hyperglycemia, which results from defective insulin action and secretion or both [1]. World Health Organization explores that the number of diabetic patients will exceed 350 million by 2030 [1]. Previous data have documented liver disease is a major cause of morbidity and mortality of type 2 diabetes patients [2,3]. It is known that the liver is a vital organ in the metabolism of carbohydrates and in maintaining glucose homeostasis during fasting and postprandial periods $[2,4]$.

Research indicates that diabetes is associated with several liver diseases. Non-Alcoholic Fatty Liver Disease (NAFLD) is the scope of chronic liver disease in patients with T2D [5], which is characterized by excess deposition of fat in the liver and associated with hepatic insulin resistance (IR) [3] and T2D risk [5]. Serum alanine aminotransferase (ALT) and gamma-glutamyltransferase (GGT) are good biomarkers of NAFLD. ALT has been considered a specific marker of liver injury, as found in high concentrations in hepatocytes [6], while GGT is present on the surface of most cell types and highly active in the liver, pancreas, and kidneys [7]. Besides, GGT is responsible for the extracellular glutathione catabolism and may be linked to oxidative stress [8] and chronic inflammation [9]; both oxidative stress and chronic inflammation are important pathways for hepatic IR and subsequently T2D development [10].

Many studies on liver enzymes and incident T2D risk were conducted in Europe [11-14] and the Asian population [15-21]. However, inconsistent findings are reported: some studies have shown that GGT and ALT are significantly associated with improved T2D prediction [15,21], while others did not [20]. Therefore, we hypothesized that the liver is the primary organ that is more susceptible to the effects of hyperglycemia-induced oxidative stress, which may lead to liver injury and subsequently chronic inflammation. To our knowledge, no previous studies addressed the association between liver enzymes and T2D risk in Yemen. Hence, this present study was aimed to assess the association between these liver enzymes and T2DM in a sample of Yemeni patients. 


\section{Subjects and Methods}

\section{Study design and subject selection}

This case-control study was carried out at the College of Medicine and Health Sciences, Hadhramout University, and the subjects were recruited from the diabetic outpatient clinic of Ibn-Sina hospital, Mukalla during the period from $1^{\text {st }}$ January to $30^{\text {th }}$ May 2020. A total of 284 Yemeni adult subjects randomly selected and recruited into this study. At recruitment, an in-person interview was conducted using a structured questionnaire to collect health-related information. The study group was subdivided into two groups: 142 healthy control subjects composed of 51 males and 91 females (age: $46.0 \pm 7.94$ yr.), and $142 \mathrm{~T} 2 \mathrm{D}$ patients composed of 64 males and 78 females (age: 54.0 $\pm 8.29 \mathrm{yr}) \mathrm{T} 2 \mathrm{D}$ patients were those who reported being diagnosed with T2D. Healthy control subjects were selected from the remaining participants who were free of T2D and were matched for age, sex, and dialect group with cases on a 1:1 ratio. Moreover, the selected healthy control subjects were screened for the presence of undiagnosed T2D at the time of blood donation by measuring fasting blood glucose (FBG). Healthy control subjects with $F B G \geq 7.0 \mathrm{mmol} / \mathrm{L}$ were excluded from the study. Written consent was obtained from each participant entered into the study. The study was approved by the Ethics Committee of the Medicine and Health Sciences College, Hadhramout University, Mukalla, Yemen. Patients with comorbidities such as chronic liver disease, chronic renal disease, cardiovascular disease, and malignancy were excluded.

\section{Data collection}

A gave questionnaire form focusing on demographic information, and diabetes history was given to all subjects. The patient's demographic data, clinical presentation, medical history, and physical findings were taken from each participant. These data are included: The patient's age, sex, smoking status (never, current or past), hypertension status (yes or no), diabetes status (yes or no), diabetes duration (years), diabetes medication, and diabetes complications. Participants were diagnosed with diabetes according to medical history, present intake of diabetes medications, or the American Diabetes Association (ADA) criteria [22]. Patients with T2DM were defined as fasting blood glucose level $\geq 126 \mathrm{mg} / \mathrm{dl}$ ( $\geq 7.0 \mathrm{mmol} / \mathrm{L}), 2$-hour postprandial plasma glucose level $\geq 200 \mathrm{mg} / \mathrm{dl}$ ( $\geq 11.1 \mathrm{mmol} / \mathrm{L})$, or $\mathrm{HbA} 1 \mathrm{c} \geq 6.5 \%$ [22]. Classification of Body Mass Index (BMI) was based on WHO [23].

\section{Anthropometric and blood pressure measurements}

Weight and height were measured according to WHO guidelines [15]. Body mass index (BMI) was calculated as weight $/ \mathrm{height}^{2}\left(\mathrm{Kg} / \mathrm{m}^{2}\right)$. Obese subjects were defined as BMI $\geq 30 \mathrm{~kg} / \mathrm{m}^{2}$ and normal-weight subjects having a BMI of 18-25 according to WHO guidelines [23]. Patients who had a blood pressure of $\geq 140 / 90 \mathrm{mmHg}$ or were taking antihypertensive medications were diagnosed with hypertension [24]. A true healthy normal ALT level ranges from 29 to $33 \mathrm{IU} / \mathrm{l}$ for males and 19 to $25 \mathrm{IU} / \mathrm{l}$ for females as classified by the American College of Gastroenterology (ACG) [25].

\section{Blood Sampling Biochemical Analysis}

Ten milliliters of the venous blood sample was obtained from consenting subjects. The blood samples were collected by vein puncture in tubes without anticoagulant. The blood samples were then transported to the laboratory immediately. The serum was then separated and stored at $-20^{\circ} \mathrm{C}$ freezers till analyses. The serum samples of matched case-control pairs were randomly placed next to each other with the case/control status blinded to the laboratory personnel and were processed and tested in the same batch. All laboratory equipment was calibrated. Thawing freezing was avoided by dividing the samples into aliquots. Plasma Fasting Blood Glucose (FBG), total cholesterol, triglycerides, and HDL-cholesterol (HDL-C) were determined enzymatically using a chemical autoanalyzer (Cobas Integra 400 Plus, Roche diagnostic GmbH, Mannheim, Switzerland), following the standard procedures as described by the manufacturer. Concentrations of LDL-cholesterol (LDL-C) were calculated using Friedwald's formula [26]. The biochemical investigations were analyzed in the National Center for Public Health Labs-Mukalla, Yemen.

\section{Statistical analysis}

The results analyzed using the statistical package for the social sciences for windows (version 24) and are expressed by Mean \pm Standard Deviation (SD) for continuous variables (normally distributed). Non-continuous variables are expressed by median (inter-quartile range) and $\mathrm{n}$ (percentage) for categorical variables. Independent Student's t-test used for normally distributed continuous variables and Wilcoxon signed-rank test for skewed continuous variables. The Pearson correlation test was performed with ALT, AST, and GGT as the dependent variables. ALT, AST, and GGT were divided into tertiles according to their distribution in the healthy control group, and the lowest tertile served as the reference group. We also used conditional logistic regression to model their associations with T2D, adjusting for age (continuous), smoking (never, current, and past smoker), and BMI (continuous) (model 1). Total cholesterol $(\mathrm{mmol} / \mathrm{L})$, triglyceride $(\mathrm{mmol} / \mathrm{L}), \mathrm{HDL}-\mathrm{C}(\mathrm{mmol} / \mathrm{L})$, and LDL-C $(\mathrm{mmol} / \mathrm{L})$ were added to model 1 as model 2 in all in tertiles. We repeated the same analysis in 176 cases and control pairs with baseline FBG $<7.0 \mathrm{mmol} / \mathrm{L}$. Conditional regression analyses were done to estimate the odds ratios (ORs) and 95\% CIs for T2D patients. The statistical analysis was conducted at a $95 \%$ confidence level, and a $\mathrm{P}$-value $<0.05$ was considered statistically significant.

\section{Results}

Descriptive statistics of anthropometric and biochemical data of the study population were studied (Table 1). T2D patients had significantly increased BMI $(\mathrm{P}=0.008)$, systolic $\mathrm{BP}(\mathrm{P} \leq 0.0001)$, diastolic $\mathrm{BP}(\mathrm{P} \leq$ $0.0001)$, FBG $(\mathrm{P} \leq 0.0001)$, total cholesterol $(\mathrm{P} \leq 0.0001)$, LDL-C $(\mathrm{P} \leq$ $0.0001)$, and GGT $(\mathrm{P}=0.016)$ compared to healthy control subjects. No significant difference was found in serum triglyceride $(\mathrm{P}=0.097)$ and ALT $(\mathrm{P}=0.07)$. Healthy control subjects had significantly increased HDL-C $(\mathrm{P}=0.021)$ and AST $(\mathrm{P}=0.001)$ compared to T2D patients. On the other hand, $31.7 \%$ of T2D patients had hypertension, whereas $6.3 \%$ of healthy control subjects had hypertension. Besides, in T2D patients, the current smokers were $4.2 \%$, and the former smokers were $3.5 \%$. According to BMI criteria, $38.7 \%$ of T2D patients were overweight and $24.6 \%$ were obese and $40.1 \%$ and $14.1 \%$ of healthy control subjects were overweight or obese, respectively.

Pearson correlation using ALT, AST, and GGT as dependent variables is presented in table 2 . Serum ALT was positively associated with FBG $(r=0.145, P=0.014)$, triglyceride $(r=0.172, P=0.004)$, AST $(\mathrm{r}=590, \mathrm{P}<0.001)$, and GGT $(\mathrm{r}=0.507, \mathrm{P}=<0.001)$ respectively. Serum GGT was positively associated with systolic BP $(\mathrm{r}=0.134, \mathrm{P}=0.024)$, diastolic BP $(\mathrm{r}=0.218, \mathrm{P}<0.001)$, FBG $(\mathrm{r}=0.216, \mathrm{P} \leq 0.0001)$, total cholesterol $(\mathrm{r}=0.196, \mathrm{P} \leq 0.0001)$, triglyceride $(\mathrm{r}=0.123, \mathrm{P}=0.038)$, LDL-C $(r=0.209, \mathrm{P} \leq 0.0001)$, and AST $(\mathrm{r}=0.366, \mathrm{P} \leq 0.0001)$ across the combined group.

Using partial correlation analysis (Table 3), controlling for age and BMI, a significant positive association between ALT with AST $(r=0.589$, $\mathrm{P} \leq 0.0001)$ and ALT $(\mathrm{r}=0.514, \mathrm{P} \leq 0.0001)$ remained significant across 
Table 1: Anthropometric and biochemical data of healthy controls and T2D patients.

\begin{tabular}{|c|c|c|c|}
\hline Variables & Healthy controls & T2D patients & P-value \\
\hline $\mathrm{N}$ & 142 & 142 & \\
\hline Age (years) & $46.0 \pm 7.94$ & $54.0 \pm 8.29$ & $\leq 0.0001$ \\
\hline Sex: male/female & $51(35.9) / 91(64.1)$ & $63(44.4) / 78(54.9)$ & \\
\hline Weight (kg) & $71.12 \pm 10.67$ & $69.61 \pm 13.83$ & $\leq 0.0001$ \\
\hline Height (cm) & $164.57 \pm 8.47$ & $159.97 \pm 10.04$ & $\leq 0.0001$ \\
\hline $\mathrm{BMI}\left(\mathrm{kg} / \mathrm{m}^{2}\right)$ & $26.31 \pm 3.95$ & $27.21 \pm 4.94$ & 0.008 \\
\hline $\mathrm{SBP}(\mathrm{mmHg})$ & $115.28 \pm 13.11$ & $128.80 \pm 20.92$ & $\leq 0.0001$ \\
\hline $\mathrm{DBP}(\mathrm{mmHg})$ & $70.45 \pm 9.02$ & $79.47 \pm 9.90$ & $\leq 0.0001$ \\
\hline \multicolumn{4}{|l|}{ BMI classification: } \\
\hline Normal weight & $65(45.8)$ & $52(36.6)$ & \\
\hline Overweight & $57(40.1)$ & $55(38.7)$ & \\
\hline Obese & $20(14.1)$ & $35(24.6)$ & \\
\hline \multicolumn{4}{|l|}{$\begin{array}{l}\text { History of } \\
\text { hypertension: }\end{array}$} \\
\hline Yes/no & $9(6.3) / 133(93.7)$ & $45(31.7) / 97(68.3)$ & \\
\hline \multicolumn{4}{|l|}{ Smoking status: } \\
\hline Never Smoker & $142(100)$ & $131(92.3)$ & \\
\hline Current Smoker & $0(0)$ & $6(4.2)$ & \\
\hline Former Smoker & $0(0)$ & $5(3.5)$ & \\
\hline FBG (mmol/L) & $5.18 \pm 0.91$ & $8.91 \pm 2.89$ & $\leq 0.0001$ \\
\hline $\begin{array}{l}\text { Total cholesterol } \\
\text { (mmol/L) }\end{array}$ & $4.70 \pm 0.77$ & $5.16 \pm 1.20$ & $\leq 0.0001$ \\
\hline $\begin{array}{l}\text { Triglyceride } \\
(\mathrm{mmol} / \mathrm{L})\end{array}$ & $1.24 \pm 0.37$ & $1.16 \pm 0.42$ & 0.097 \\
\hline $\mathrm{HDL}-\mathrm{C}(\mathrm{mmol} / \mathrm{L})$ & $1.67 \pm 0.42$ & $1.57 \pm 0.34$ & 0.021 \\
\hline LDL-C (mmol/L) & $2.77 \pm 0.80$ & $3.35 \pm 1.17$ & 0.001 \\
\hline ALT (IU/L) & $13.1(8.37-19.3)$ & $11.6(7.3-16.8)$ & 0.07 \\
\hline AST (IU/L) & $21.2(17.8-28.7)$ & $16.4(13.3-21.7)$ & 0.001 \\
\hline GGT (IU/L) & $25.1(16.8-34.7)$ & $29.2(18.4-49.7)$ & $\leq 0.0001$ \\
\hline
\end{tabular}

Data were presented as mean \pm SD for normal continuous variables and median (inter quartile range) for continuous non-normal variables. Independent sample T-test for normally distributed continuous variables and Mann-Whitney $U$ test for skewed continuous variables. P-value $<0.05$ was considered statistically significant.

BMI, Body Mass Index; SBP, Systolic Blood Pressure; DBP, Diastolic Blood Pressure; FBG, Fasting Blood Glucose; HDL-C, High-Density Lipoprotein Cholesterol; LDL-C, Low-Density Lipoprotein Cholesterol; ALT, Alanine Aminotransferase; AST, Aspartate Aminotransferase; GGT, Gamma-Glutamyltransferase.

the combined group, While, the association between ALT with FBG and triglyceride was no longer significant. Using the same analysis, the association between GGT with systolic BP $(\mathrm{r}=0.124, \mathrm{P}=0.038)$, diastolic BP ( $\mathrm{r}=0.213, \mathrm{P} \leq 0.0001)$, FBG $(\mathrm{r}=0.213, \mathrm{P} \leq 0.0001)$, total cholesterol $(\mathrm{r}=0.199, \mathrm{P}=0.001)$, triglyceride $(\mathrm{r}=0.127, \mathrm{P}=0.033)$, and LDL-C $(r=0.208, P \leq 0.0001)$ remained significant before and after age and $\mathrm{BMI}$ as adjustment.
Table 2: Pearson correlation using ALT, AST and GGT as dependent variables in the combined study group.

\begin{tabular}{|c|c|c|c|c|c|c|}
\hline \multirow[t]{2}{*}{$N=284$} & \multicolumn{2}{|c|}{ ALT } & \multicolumn{2}{|c|}{ AST } & \multicolumn{2}{|c|}{ GGT } \\
\hline & $r$ & P-value & $r$ & P-value & $r$ & P-value \\
\hline Age (years) & -0.046 & 0.443 & 0.010 & 0.860 & 0.047 & 0.433 \\
\hline Sex (M/F) & $0.119^{*}$ & 0.046 & 0.116 & 0.050 & 0.016 & 0.789 \\
\hline Weight (kg) & -0.001 & 0.989 & -0.008 & 0.895 & -0.004 & 0.945 \\
\hline Height (cm) & 0.098 & 0.101 & 0.071 & 0.235 & -0.058 & 0.334 \\
\hline $\mathrm{BMI}\left(\mathrm{kg} / \mathrm{m}^{2}\right)$ & -0.070 & 0.241 & -0.059 & 0.326 & 0.033 & 0.538 \\
\hline $\mathrm{SBP}(\mathrm{mmHg})$ & -0.037 & 0.533 & -0.058 & 0.334 & $0.134^{*}$ & 0.024 \\
\hline $\mathrm{DBP}(\mathrm{mmHg})$ & 0.013 & 0.830 & -0.080 & 0.178 & $0.218^{* *}$ & $\leq 0.0001$ \\
\hline $\begin{array}{l}\text { FBG } \\
(\mathrm{mmol} / \mathrm{L})\end{array}$ & $0.145^{*}$ & 0.014 & -0.067 & 0.260 & $0.216^{* *}$ & $\leq 0.0001$ \\
\hline $\begin{array}{l}\text { Total } \\
\text { cholesterol } \\
\text { (mmol/L) }\end{array}$ & 0.027 & 0.653 & 0.081 & 0.176 & $0.196^{*}$ & $\leq 0.0001$ \\
\hline $\begin{array}{l}\text { Triglyceride } \\
\text { (mmol/L) }\end{array}$ & $0.172^{* *}$ & 0.004 & 0.087 & 0.141 & $0.123^{*}$ & 0.038 \\
\hline $\begin{array}{l}\mathrm{HDL}-\mathrm{C} \\
(\mathrm{mmol} / \mathrm{L})\end{array}$ & -0.091 & 0.124 & -0.023 & 0.699 & -0.064 & 0.285 \\
\hline $\begin{array}{l}\text { LDL-C } \\
(\mathrm{mmol} / \mathrm{L})\end{array}$ & 0.047 & 0.429 & 0.082 & 0.170 & $0.209^{* *}$ & $\leq 0.0001$ \\
\hline ALT (IU/L) & & & $0.590^{* *}$ & $\begin{array}{c}\leq \\
0.0001\end{array}$ & $0.507^{* *}$ & $\leq 0.0001$ \\
\hline AST (IU/L) & $0.590^{* *}$ & $\leq 0.0001$ & & & $0.366^{* *}$ & $\leq 0.0001$ \\
\hline GGT (IU/L) & $0.507^{* *}$ & $\leq 0.0001$ & $0.366^{* *}$ & $\begin{array}{c}\leq \\
0.0001\end{array}$ & & \\
\hline
\end{tabular}

Pearson correlation coefficient with corresponding $p$-value ( $p<0.05$ is considered a significant).

** Correlation is significant at the 0.01 level (2-tailed).

* Correlation is significant at the 0.05 level (2-tailed).

BMI, Body Mass Index; SBP, Systolic Blood Pressure; DBP, Diastolic Blood Pressure; FBG, Fasting Blood Glucose; TC, Total Cholesterol; TG, Triglyceride; HDL-C, High-Density Lipoprotein Cholesterol; LDL-C, LowDensity Lipoprotein Cholesterol; ALT, Alanine Aminotransferase; AST, Aspartate Aminotransferase; GGT, Gamma-Glutamyltransferase.

Furthermore, the relationship between liver enzymes and incident T2D risk was studied. Higher ALT and GGT levels were associated with higher T2D risk (OR comparing extreme tertiles 2.75 (95\% CI 2.01 to $3.48, \mathrm{P}=0.006 ; 1.17$ (95\% $\mathrm{CI} 1.83$ to $6.42, \mathrm{P}=0.022$ respectively) in the final model. While, AST levels showed no significant association both in model 1 1.02; (95\% CI 0.23 to $4.22, \mathrm{P}=0.550$ ) and model 2 1.22(0.02 to 4.79, $\mathrm{P}=0.306$ ) (Table 4). In contrast, ALT and GGT levels showed no significant association among case-control pairs with FBG $<7.0 \mathrm{mmol} / \mathrm{L}$, while higher AST levels were positively associated with increased T2D risk among case-controls with FBG $<7.0 \mathrm{mmol} / \mathrm{L}$ in the final model (or comparing highest versus lowest tertile 1.578(95\% CI 2.718 to $3.466, \mathrm{P}=0.023$ ) (Table 4 ).

\section{Discussion}

Although the incidence of diabetes is increasing worldwide and its prevalence is higher in developing countries, no studies have examined the relationship between elevated liver enzymes and T2D risk in Yemeni patients. Our research, therefore, was focused on the liver as the vital organ contributing to glucose homeostasis during the fasting and postprandial stage. Also, most people aged $\geq 45$ years in developing countries have diabetes [27]. These findings were 
Table 3: Pearson correlation using ALT, AST and GGT as dependent variables in after Age and BMI adjustment as a covariance.

\begin{tabular}{|c|c|c|c|c|c|c|}
\hline \multirow[t]{2}{*}{$N=284$} & \multicolumn{2}{|c|}{ ALT } & \multicolumn{2}{|c|}{ AST } & \multicolumn{2}{|c|}{ GGT } \\
\hline & $r$ & P-value & $\mathbf{r}$ & P-value & $r$ & P-value \\
\hline $\operatorname{Sex}(M / F)$ & 0.116 & 0.051 & 0.114 & 0.055 & 0.017 & 0.772 \\
\hline SBP (mmHg) & -0.018 & 0.764 & -0.053 & 0.377 & $0.124^{*}$ & 0.038 \\
\hline DBP (mmHg) & 0.024 & 0.686 & -0.078 & 0.194 & $0.213^{* *}$ & $\begin{array}{c}\leq \\
0.0001\end{array}$ \\
\hline FBG $(\mathrm{mmol} / \mathrm{L})$ & 0.161 & 0.007 & -0.074 & 0.213 & $0.213^{* *}$ & $\begin{array}{c}\leq \\
0.0001\end{array}$ \\
\hline $\begin{array}{l}\text { Total } \\
\text { cholesterol } \\
\text { (mmol/L) }\end{array}$ & 0.027 & 0.652 & 0.085 & 0.155 & 0.199 & 0.001 \\
\hline $\begin{array}{l}\text { Triglyceride } \\
\text { (mmol/L) }\end{array}$ & 0.171 & 0.004 & 0.090 & 0.130 & 0.127 & 0.033 \\
\hline HDL-C (mmol/L) & -0.104 & 0.081 & -0.026 & 0.668 & -0.056 & 0.351 \\
\hline LDL-C (mmol/L) & 0.052 & 0.388 & 0.087 & 0.147 & 0.208 & $\begin{array}{c}\leq \\
0.0001\end{array}$ \\
\hline ALT (IU/L) & & & $0.589^{* *}$ & $\begin{array}{c}\leq \\
0.0001\end{array}$ & $0.514^{* *}$ & $\begin{array}{c}\leq \\
0.0001\end{array}$ \\
\hline AST (IU/L) & $0.589^{* *}$ & $\begin{array}{c}\leq \\
0.0001\end{array}$ & & & $0.368^{* *}$ & $\begin{array}{c}\leq \\
0.0001\end{array}$ \\
\hline GGT (IU/L) & $0.514^{* *}$ & $\begin{array}{c}\leq \\
0.0001\end{array}$ & $0.368^{* *}$ & $\begin{array}{c}\leq \\
0.0001\end{array}$ & & \\
\hline
\end{tabular}

Pearson correlation coefficient with corresponding $p$-value ( $p<0.05$ is significant).

**Correlation is significant at the 0.01 level (2-tailed).

*Correlation is significant at the 0.05 level (2-tailed).

BMI, Body Mass Index; SBP, Systolic Blood Pressure; DBP, Diastolic Blood Pressure; FBG, Fasting Blood Glucose; HDL-C, High-Density Lipoprotein Cholesterol; LDL-C, Low-Density Lipoprotein Cholesterol; ALT, Alanine Aminotransferase; AST, Aspartate Aminotransferase; GGT, Gamma-Glutamyltransferase.

convenient with our study showed that T2D patients had significantly higher mean age compared to healthy control subjects (Table 1).

Our present findings also observed significantly increased BMI, systolic BP, and diastolic BP in T2D patients than healthy control subjects. The current results also showed that serum FBG, total cholesterol, and LDL-C were significantly higher in T2D patients than healthy control subjects. At the same time, no significant difference among both groups for serum triglycerides was found. In contrast, HDL-C was significantly lower in T2D patients. Our study further revealed higher levels of GGT in T2D patients. At the same time, AST was considerably lower in T2D patients. Besides, no significant difference between both groups for ALT was observed.

Our study also revealed positive correlations between GGT with FBG, total cholesterol, triglycerides, and LDL-C across the combined group before and after adjustment for age and BMI. The association between ALT with FBG and triglycerides was no longer significant after adjustment for age and BMI. Such a positive relationship between liver enzymes and blood lipid profile in T2D patients has been observed in previous studies [4,28-32]. This finding supports the role of hepatic IR in NAFLD's pathogenesis in patients with T2D $[6,33]$.

Moreover, Cho NH, et al. reported a correlation between ALT activity and increased fatty liver [16]. The impairment of the normal process of synthesis and elimination of triglycerides may progress to fibrosis, cirrhosis, and hepatocellular carcinoma
[34,35]. A triglyceride is a significant form of lipids stored in the liver of patients with NAFLD.

In addition to its effect on lipid metabolism, insulin also contributes a pro-inflammatory effect to liver abrasion [29]. Thus, inflammation contributes to IR. Moreover, Pro-inflammatory cytokines and transcription factors are highly expressed in white adipose tissue and the liver. In contrast, obesity, a state of chronic low-grade inflammation and a risk factor for IR and NAFLD, is induced by over nutrition. It is a primary cause of decreased insulin sensitivity. Obesity leads to lipid accumulation and activates the c-Jun N-terminal kinase (JNK) and nuclear factor-kappa B (NF-kB) signaling pathways, which consequently increase the production of pro-inflammatory cytokines, such as tumor necrosis factor-alpha (TNF- $\alpha$ ) and interleukin-6 (IL6) [36]. Besides, various adipose tissue-derived proteins, such as adiponectin and leptin, are considered significant links between obesity, IR, and related inflammatory disorders [37].

GGT is known as a marker of hepatobiliary disorders and is associated with other pathological conditions like diabetes. Free radicals generated by diabetes consume glutathione which induces the increased expression of GGT in hepatocytes. Various studies have suggested the association of GGT concentrations with T2D [37-41], and hyperlipidemia [42]. These findings agree with our study; GGT was significantly associated with the hyperglycemic and hyperlipidemia profile. We observed ALT and GGT together were positively correlated. Moreover, some data also reported elevated GGT levels with ALT in T2D patients with dyslipidemia [39,40,43]. Even though we did not confirm the presence of fatty liver by ultrasound techniques, we showed the relationship of ALT, AST, and GGT with the predictors of diabetes and lipid profile parameters, presenting hepatocellular injury.

A study of male Korean workers found that AST was independently associated with diabetes [44], while in a study of male Japanese office workers; AST was not associated with T2D risk [40]. Some studies also reported that ALT is a significant predictor of diabetes while AST is not [45]. These findings agree with our conclusions as AST does not show a considerable relationship with the studied parameters. Besides, Clark JM, et al. also suggested that mild or chronic elevation of these aminotransferases may be due to NAFLD [46,47]. However, our study is limited to the standard method of liver biopsy for the prediction of NAFLD. Still, it goes with the analysis of the third national health and nutritional examination survey, where individuals with NAFLD have elevated aminotransferases.

Besides, our study also found that increased ALT and GGT levels improve the prediction of T2D risk. Several previous studies supported this: a meta-analysis reported a pooled relative risk of 1.34 (95\% CI 1.27 to 1.42) comparing the highest versus lowest tertiles of GGT levels [48] and 1.66 (95\% CI 1.31 to 2.09) for ALT [49]. Besides, a case-control study in a Chinese population also reported higher levels of ALT and GGT with increased risk of T2D 2.00 (1.01 to 3.96; ALT) and 2.38 (1.21 to 4.66; GGT) [21]. A Mendelian randomization study further provided evidence for the relationship between higher GGT levels and the hepatic IR studies [50]. In contrast, our study did not observe any relationship of AST incident T2D risk, which was consistent with previous studies $[18,30,38,51]$. This may be due to a lack of specificity of AST for liver diseases [18]. However, one Korean study showed a positive correlation between GGT/ALT and T2D risk among patients without fatty liver, suggesting alternative pathways exist [17]. Thus, increased GGT and ALT levels were linked to T2D development as surrogate NAFLD measures [52]. NAFLD also may indicate fat deposition in other organs such as skeletal muscle, myocardium, and 
Table 4: Odds ratio $(95 \% \mathrm{Cl})$ of T2D associated with different levels of liver enzymes. Data are presented as odds ratio at $95 \%$ confidence intervals.

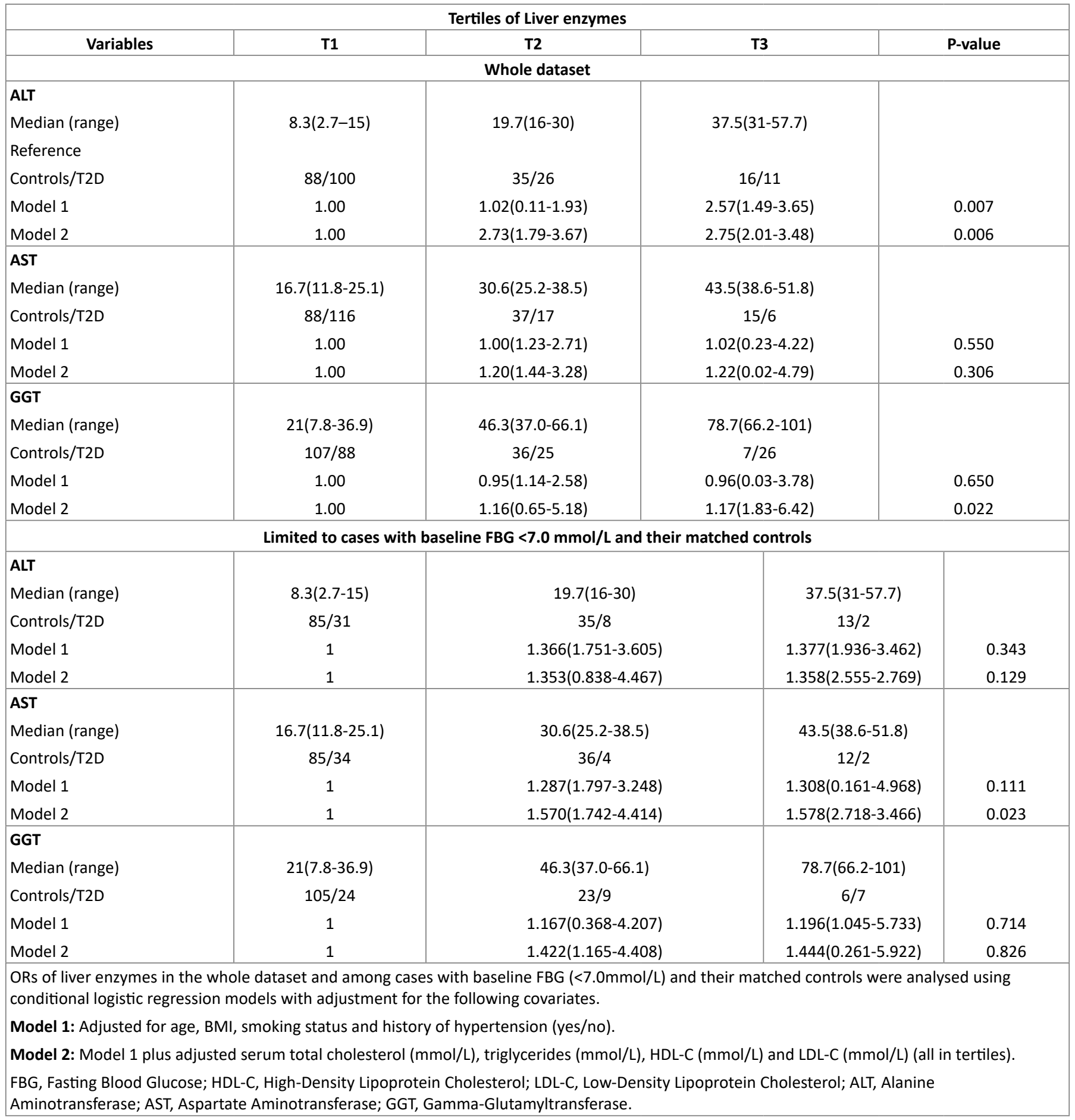

the pancreas, which predispose individuals to T2D risk [52]. Moreover, research evidence showed that GGT and ALT's relations with T2D risk were also independent of other vital pathologies in T2D development, such as whole-body insulin resistance $[3,45]$ and blood lipid profile [3,14-16].

The present study's strength included adjustment for wellestablished diabetes risk factors, including BMI, blood lipids, and hypertension, and using comprehensive statistical methods (Pearson correlation coefficient and regression analysis) to explore the predictive utility of liver enzymes with other risk factors. However, there are some limitations: Our sample size may be small and thus underpowered to detect the interaction with ALT and GGT. We measured liver enzymes only once and may not represent a long-term profile. We did not measure hepatitis $\mathrm{B}$ and $\mathrm{C}$ infection, resulting in elevated liver enzymes. We did not measure hs-CRP, insulin, C-peptide, leptin, and adiponectin as predictive biomarkers linked between obesity, hepatic IR, and related inflammatory disorders in T2D patients. Thus, a further large sample size with measurements of insulin, hsCRP, leptin, adiponectin, and interleukins are required to confirm these correlations. In conclusion, higher ALT and GGT are positively 
associated with a higher risk of T2D in Yemeni patients. Thus, routine screening of liver enzymes in T2D patients is recommended to detect liver disorders.

\section{Conclusions}

Markedly elevated ALT and GGT are positively associated with a higher risk of T2D in Yemeni patients and may be used as predictive biomarkers in developing T2D risk. Thus, routine screening of ALT and GGT in T2D patients is recommended to detect liver disorders.

\section{Data Availability}

All requests for data access should be addressed to the corresponding author. Proposals requesting data access will have to specify how they plan to use the data.

\section{Conflict of Interest}

The authors declare no conflicts of interest.

\section{Acknowledgments}

The authors are grateful to Al-Huda Medical Agency, Mukalla, Yemen, for funding the study and the Ibn-Sina Hospital, Mukalla, Yemen for technical support. Also, we are thankful to the physicians and nurses who recruited and collected the data of the participants. Special thanks to Students of Medical Laboratory Sciences Department (Ali Alqaaiti, Saleh Daiban, Sabri Barafah, Afaf Aldibani, Safa Basawaid, and Noor Zahfan) for the performance of data and sample collection, data entry, and biochemical investigations. Special thanks to Ms. Nasiba Al-Aidros for the statistical analysis.

\section{References}

1. WHO (1999) Definition, diagnosis and classification of diabetes mellitus and its complications: Report of a WHO consultation. Geneva: World Health Organization.

2. Levinthal GN, Tavill AS (1999) Liver Disease and Diabetes Mellitus. Clin Diab 17.

3. Hanley AJG, Williams K, Festa A, Wagenknecht LE, D'Agostino RBJ, et al. (2004) Elevations in markers of liver injury and risk of type 2 diabetes: the insulin resistance atherosclerosis study. Diab 53: 26232632.

4. Jameil NAL, Khan FA, Arjumand S, Khan MF, Tabassum H (2014) Associated liver enzymes with hyperlipidemic profile in type 2 diabetes patients. Int J Clin Exp Pathol 7: 4345-4349.

5. Ballestri S, Zona S, Targher G, Romagnoli D, Baldelli E (2016) Nonalcoholic fatty liver disease is associated with an almost twofold increased risk of incident type 2 diabetes and metabolic syndrome. Evidence from a systematic review and meta-analysis. J Gastroenterol Hepatol 31: 936-44.

6. Tolman KG, Fonseca V, Dalpiaz A, Tan MH (2007) Spectrum of liver disease in type 2 diabetes and management of patients with diabetes and liver disease. Diabetes Care 30: 734-743.

7. Giannini EG, Testa R, Savarino V (2005) Liver enzyme alteration: a guide for clinicians. CMAJ 172: 367-379.

8. Hanigan MH, Frierson Jr HF (1996) Immunohistochemical detection of gamma-glutamyl transpeptidase in normal human tissue. J Histochem Cytochem 44: 1101-1108.

9. Turgut O, Tandogan I (2011) Gamma-glutamyltransferase to determine cardiovascular risk: shifting the paradigm forward. J Atheroscler Thromb 18: 177-181.
10. Lee LD, Jacobs DR Jr (2005) Association between serum gammaglutamyltransferase and C-reactive protein. Atherosclerosis 178: 327-330.

11. Fraser A, Harris R, Sattar N, Ebrahim S, Smith GD, et al. (2009) Alanine aminotransferase, gamma-glutamyltransferase, and incident diabetes: the British Women's Heart and Health Study and meta-analysis. Diabetes Care 32: 741-750.

12. Goessling W, Massaro JM, Vasan RS, D'Agostino Sr RB, Ellison RC, et al. (2008) Aminotransferase levels and 20-year risk of metabolic syndrome, diabetes, and cardiovascular disease. 135: 1935-44.

13. Monami M, Bardini G, Lamanna C, Pala L, Cresci B, et al. (2008) Liver enzymes and risk of diabetes and cardiovascular disease: results of the Firenze Bagno a Ripoli (FIBAR) study. Metabolism 57: 387-392.

14. Sattar N, Scherbakova O, Ford I, O'Reilly DST, Stanley A, et al. ( 2004) Elevated alanine aminotransferase predicts new-onset type 2 diabetes independently of classical risk factors, metabolic syndrome, and C-reactive protein in the west of Scotland coronary prevention study. Diabetes 53: 2855-2860.

15. Doi $Y$, Kubo M, Yonemoto K, Ninomiya T, Iwase M, et al. (2007) Liver enzymes as a predictor for incident diabetes in a Japanese population: the Hisayama study. Obesity 15: 1841-1850.

16. Cho NH, Jang HC, Choi SH, Kim HR, Lee HL, et al. (2007) Abnormal liver function test predicts type 2 diabetes: a community-based prospective study. Diabetes Care 30: 2566-2568.

17. Kim CH, Park JY, Lee KU, Kim JH, Kim HK, et al. (2009) Association of serum gamma-glutamyltransferase and alanine aminotransferase activities with risk of type 2 diabetes mellitus independent of fatty liver. Diabetes Metab Res Rev 25: 64-69.

18. Jiamjarasrangsi W, Sangwatanaroj S, Lohsoonthorn V, Lertmaharit S (2008) Increased alanine aminotransferase level and future risk of type 2 diabetes and impaired fasting glucose among the employees in a university hospital in Thailand. Diabetes Metab 34: 283-289.

19. Tohidi M, Hadaegh HHF, Mehrabi Y, Azizi F (2008) Association of liver enzymes with incident type 2 diabetes: a nested case control study in an Iranian population. BMC Endocr Disord 8: 5.

20. Schulze MB, Weikert $\mathrm{C}$, Pischon $\mathrm{T}$, Bergmann MM, Al-Hasani $\mathrm{H}$, et al. (2009) Use of multiple metabolic and genetic markers to improve the prediction of type 2 diabetes: the EPIC-Potsdam Study. Diabetes Care Nov 32: 2116-2119.

21. Wang YL, Koh WP, Yuan JM, Pan A (2016) Association between liver enzymes and incident type 2 diabetes in Singapore Chinese men and women. BMJ Open Diabetes Res 4: e000296.

22. American Diabetes Association (2016) Standards of medical care in diabetes. Diabetes Care 39: 101-106.

23. WHO (1995) Physical status: the use and interpretation of anthropometry Physical status: the use of and interpretation of anthropometry, report of a WHO expert committee, Geneva. WHO technical report series 854: 321-344.

24. Chobanian AV, Bakris GL, Black HR, Cushman WC, Green LA, et al. (2003) Seventh report of the Joint National Committee on Prevention, Detection, Evaluation, and Treatment of High Blood Pressure. Hypertension 42: 1206-1252.

25. Kwo PY, Cohen SM, Lim JK (2017) ACG clinical guideline: evaluation of abnormal liver chemistries. Am J Gastroenterol 112: 18-35.

26. Friedewald WT, Levy RI, Fredrickson DS (1972) Estimation of the concentration of low-density lipoprotein cholesterol in plasma, without use of the preparative ultracentrifuge. Clin Chem 18: 499502. 
27. Nwarfor A, Owhoji A (2001) The prevalence of diabetes mellitus in port-Harcourt correlates with the socio-economic status. J Appl Sci Environ Mgt 5: 75-77.

28. Jain HR, Shetty V, Singh GS, Shetty S (2016) A Study of Lipid Profile in Diabetes Mellitus. Int J Sci Stud 4: 56-61.

29. Han N, Soe HHK, Htet A (2012) Determinants of Abnormal Liver Function Tests in Diabetes Patients in Myanmar. Int J Diab Res 1: 36-41.

30. Belay Z, Daniel S, Tedla K, Gnanasekaran N (2014) Impairment of liver function tests and lipid profiles in type 2 diabetic patients treated at the diabetic center in Tikur Anbessa specialized teaching hospital (Tasth), Addis Ababa, Ethiopia. J Diabetes Metab 5: 11.

31. Adeniran SA, Dolapo PO, Oluwole AB, Niran-Atiba TA, Jimoh AK (2013) Liver Enzymes and Lipid Profile among Type 2 Diabetic Patients in Osogbo, Nigeria. Greener J Med Sci 3: 174-178.

32. Dahman LSB, Humam MA, Barahim OH, Barahman OM, Balfas MA (2021) Association between liver enzymes and dyslipidemia in Yemeni patients with type two diabetes mellitus. J Diabetes Mellitus 11: 41-51

33. Nannipieri M, Gonzales C, Baldi S, Posadas R, Williams K, et al. (2005) Liver enzymes, the metabolic syndrome, and incident diabetes. Diabetes Care 28: 1757-1762.

34. Tolman KG, Fonseca V, Tan MH, Dalpiaz A (2004) Narrative review: hepatobiliary disease in type 2 diabetes mellitus. Ann Intern Med 141: 946-956.

35. Chatila R, West AB (1996) Hepatomegaly and abnormal liver tests due to glycogenesis in adults with diabetes. Med Balt 75: 327-333.

36. Sharma M, Vikram NK, Misra A, Bhatt SP, Tarique M (2013) Assessment of 11- $\beta$ hydroxysteroid dehydrogenase (11- $\beta$ HSD1) $4478 T>G$ and tumor necrosis factor- $\alpha$ (TNF- $\alpha$ )-308G $>A$ polymorphisms with obesity and insulin resistance in Asian Indians in North India. Mol Biol Rep 40: 6261-6270.

37. Chen Z, Yu R, Xiong Y, Du F, Zhu S (2017) A vicious circle between insulin resistance and inflammation in nonalcoholic fatty liver disease. Lipids Health Dis 16: 203.

38. Lee DH, Silventonein K, Jacobs DR, Jousilahti P, Tuomileto J (2014) gamma-Glutamyltransferase, obesity, and the risk of type 2 diabetes: observational cohort study among 20,158 middle-aged men and women. J Clin Endocrinol Metab 89: 5410-5414.

39. Lee DH, Ha MH, Kim JH, Christiani DC, Steffes M (2003) Gammaglutamyltransferase and diabetes--a 4 year follow-up study. Diabetologia 46: 359-364.
40. Nakanishi N, Suzuki K, Tatara K (2004) Serum gamma glutamyltransferase and risk of metabolic syndrome and type 2 diabetes in middle aged Japanese men. Diabetes Care 27: 14271432.

41. Lee DH, Jacobs Jr DR, Gross M, Kiefe $\mathrm{Cl}$, Roseman J, et al. (2003) Gamma glutamyltransferase is a predictor of incident diabetes and hypertension: the Coronary Artery Risk Development in Young Adults (CARDIA) Study. Clin Chem 49: 1358-1366.

42. Sakuta H, Suzuki T, Yasuda H, Ito T (2005) Gamma glutamyltransferase and airflow obstruction in middle-aged men. Eur J Intern Med 16 348-351.

43. Marchesini G, Brizi M, Bianchi G, Tomassetti S, Bugianesi E, et al. (2001) Nonalcoholic fatty liver disease: a feature of the metabolic syndrome. Diabetes 50: 1844-1850.

44. Ahn HR, Shin MH, Nam HS, Park KS, Lee YH, et al. (2014) The association between liver enzymes and risk of type 2 diabetes: the Namwon study. Diabetol Metab Syndr 6: 14

45. Vozarova B, Stefan N, Lindsay RS, Saremi A, Pratley RE, et al (2002) High alanine aminotransferase is associated with decreased hepatic insulin sensitivity and predicts the development of type 2 diabetes. Diabetes 51: 1889-1895.

46. Clark JM, Diehl AM (2003) Nonalcoholic fatty liver disease: an under recognized cause of cryptogenic cirrhosis. JAMA 289: 3000-3004.

47. Clark JM, Brancati FL, Diehl AM (2003) The prevalence and etiology of elevated aminotransferase levels in the United States. Am J Gastroenterol 98: 960-967.

48. Kunutsor SK, Abbasi A, Adler Al (2014) Gamma-glutamyl transferase and risk of type II diabetes: an updated systematic review and doseresponse meta-analysis. Ann Epidemiol 24: 809-816.

49. Kunutsor SK, Apekey TA, Walley J (2013) Liver aminotransferases and risk of incident type 2 diabetes: a systematic review and metaanalysis. Am J Epidemiol 178: 159-171.

50. Conen D, Vollenweider P, Rousson V, Marques-Vidal P, Paccaud F, et al. (2010) Use of a Mendelian randomization approach to assess the causal relation of gamma-glutamyltransferase with blood pressure and serum insulin levels. Am J Epidemiol 172: 1431-1441.

51. Wannamethee SG, Papacosta O, Whincup PH, Thomas MC, Carson C, et al. (2011) The potential for a two-stage diabetes risk algorithm combining non-laboratory-based scores with subsequent routine non-fasting blood tests: results from prospective studies in older men and women. Diabet Med 28: 23-30.

52. Unger RH (2003) Mini review: weapons of lean body mass destruction: the role of ectopic lipids in the metabolic syndrome. Endocrinology 144: 5159-5165. 